Revista de Investigación

Núm. 33

Académica sin Frontera

https://revistainvestigacionacademicasinfrontera.unison.mx/index.php/RDIASF

Recibido el 14 de abril de 2020. Dictaminado mediante arbitraje favorablemente 9 de julio de 2020 .

\title{
Opinión de expertos con respecto al emprendimiento en PyMES en Hermosillo, Sonora.
}

\author{
${ }^{1}$ Dr. Fco. Javier Espinoza Valencia \\ ORCID: 0000-0001-6999-5913 \\ Celular: 662-350-88-17 \\ francisco.espinoza@unison.mx
}

\author{
${ }^{2}$ Dr. Isidro Real Pérez \\ Celular: (622) 56-25-16 \\ ireal@pitic.uson.mx
}

\author{
${ }^{3}$ María Candelaria \\ González González \\ Celular: 6621 12-06-28 \\ cande@pitic.uson.mx
}

\section{Resumen}

La presente investigación se realizó mediante un enfoque cuantitativo y de corte transversal, para conocer la opinión de los expertos sobre el emprendimiento en PyMES en la ciudad de Hermosillo, Sonora en México, para lo que se tomó un muestreo por conveniencia sobre las incubadoras-expertos, de los que se recopiló la información mediante instrumento de recolección de datos y capturados en el softwere estadístico IBM.SPSS.Statistics.v21 en el cual se hace el análisis descriptivo y de frecuencias para identificar los aspectos que los expertos consideran deben tomarse en cuenta a la hora de emprender. La apreciación de los expertos demuestra que no existe la disposición de recursos para las empresas Pymes, no hay claridad sobre política o subsidio, programas de apoyo, dentro del sistema educativo básico no hay programas para formación de emprendedores, no hay disposición para la obtención de recursos para nueva tecnología, lo que sí hay es: la manera de realizar operaciones con clientes o proveedores en el extranjero, los servicios básicos e infraestructura de comunicaciones y además están de acuerdo en que la tecnología es el medio por el cual las empresas se vuelven más competitivas y logran un crecimiento sostenido; por lo que lo podemos concluir que, los emprendedores están en disposición de aperturar nuevas empresas pero las condiciones no favorecen hasta cierto grado, un ambiente propicio para hacerlo.

Palabras clave: Emprendedores, Gobierno, Expertos. 

https://revistainvestigacionacademicasinfrontera.unison.mx/index.php/RDIASF

Recibido el 14 de abril de 2020. Dictaminado mediante arbitraje favorablemente 9 de julio de 2020.

\section{Summary}

The present investigation was carried out using a quantitative and cross-sectional approach, to know the opinion of the experts on entrepreneurship in SMEs in the city of Hermosillo, Sonora in Mexico, for which a convenience sampling was taken on the incubators-experts, from which the information was collected by means of a data collection instrument and captured in the statistical software IBM.SPSS.Statistics.v21 in which the descriptive and frequency analysis is performed to identify the aspects that the experts consider should be taken into account when undertaking. The appreciation of the experts shows that there is no provision of resources for SMEs, there is no clarity on policy or subsidy, support programs, within the basic educational system there are no programs for training entrepreneurs, there is no provision for obtaining resources for new technology, what we do have is: the way to carry out operations with clients or suppliers abroad, basic services and communications infrastructure, and they also agree that technology is the means by which companies become more competitive and achieve sustained growth; reason why we can conclude that, the entrepreneurs are in disposition to open new companies but the conditions do not favor to a certain degree, a favorable environment to do it.

Key words: Entrepreneurs, Government, Experts. 
Año 13.

Revista de Investigación

Núm. 33

Académica sin Frontera

https://revistainvestigacionacademicasinfrontera.unison.mx/index.php/RDIASF

Recibido el 14 de abril de 2020. Dictaminado mediante arbitraje favorablemente 9 de julio de 2020 .

\section{Introducción}

El emprendimiento a nivel internacional ha generado mayor importancia, sobre todo porque contribuye al auto empleo, y la generación de nuevos empleos, y un mayor desarrollo de las naciones, por ello existen organismos a nivel internacional que se interesan por saber cuáles son las condiciones propicias para emprender y que las personas puedan iniciar una nueva empresa.

Un ejemplo claro de esta preocupación es el estudio denominado Monitor Global de Emprendedurismo (GEM), por sus siglas en Inglés, que mide a nivel internacional el fenómeno, adaptando la metodología del organismo de acuerdo con las características de cada país, debido a que sus condiciones políticas, económicas y sociales son muy diferentes entre sí. Inclusive resultan diferentes las mismas regiones que conforman un país, por lo que los resultados arrojados, en ocasiones parecen no ser tan certeros por que las muestras a las que se les aplica los instrumentos en ocasiones son muy reducidas y por ello parecen ser no tan confiables.

Para México los resultados generados parecen ser muy optimistas pero las condiciones no son las mismas en las diferentes entidades federativas, por ello, el interés de conocer la opinión de los expertos sobre las condiciones regionales imperantes para poder emprender.

\section{Justificación}

Lo que justifica realizar este trabajo, es la necesidad de identificar cuáles son las condiciones imperantes en Hermosillo, Sonora, sobre todo, considerando que es 
Año 13.

Revista de Investigación

Núm. 33

Académica sin Frontera

https://revistainvestigacionacademicasinfrontera.unison.mx/index.php/RDIASF

Recibido el 14 de abril de 2020. Dictaminado mediante arbitraje favorablemente 9 de julio de 2020.

necesario fomentar el espíritu emprendedor, y para ello, se requiere conocer la opinión de expertos en materia de emprendimiento y apertura y desarrollo de empresas.

\section{Contexto Nacional}

Las micro, pequeñas y medianas empresas son relevantes en México, en todo lo que se refiere a producto, como personal ocupado y a número de establecimientos. Según los resultados preliminares de los censos económicos 2014, había 5, 654, 012 unidades que realizaban alguna actividad económica y en las cuales trabajaban 29, 642, 421 personas. De estos totales, $98.6 \%$ de las unidades y $91.9 \%$ del personal ocupado correspondieron en conjunto a la industria manufacturera, al comercio y a los servicios.

De acuerdo con la clasificación del Instituto Nacional de Estadística y Geografía (INEGI), las microempresas conformaron el grupo más numeroso, al contar con $92.7 \%$ de los establecimientos totales en manufactura, $97.2 \%$ en comercio y $94.5 \%$ en servicio en el año 2008, ya que la pequeña y mediana empresa tuvieron una participación minoritaria.

\section{Contexto Estatal}

Los resultados de los Censos Económicos 2014, dan cuenta de 90642 unidades económicas existentes en el Estado de Sonora, las cuales ocuparon a 619690 personas. 
Año 13.

Revista de Investigación

Núm. 33

Académica sin Frontera

https://revistainvestigacionacademicasinfrontera.unison.mx/index.php/RDIASF

Recibido el 14 de abril de 2020. Dictaminado mediante arbitraje favorablemente 9 de julio de 2020.

\section{Contexto Municipal}

Hermosillo, económicamente fue el principal municipio de Sonora, participó con el $31.7 \%$ de las unidades económicas, el $35.3 \%$ de personal ocupado, el $35.8 \%$ de las remuneraciones y el $53.6 \%$ de la producción bruta total del estado.

\section{Incubadoras de empresas}

El concepto de incubadora de empresas dio sus primeros pasos en la década de los 50s en Silicon Valley, California, a partir de las iniciativas de la Universidad de Stanford, la cual creo un parque industrial y, posteriormente, un parque tecnológico (Stanford Research Park), con el objeto de promover la transferencia de tecnología desarrollada en la universidad hacia las empresas y la creación de nuevas empresas intensivas en tecnología, principalmente del sector eléctrico-----

En México las incubadoras nacen en 1990 en la ciudad de Ensenada Baja California. Del año 2000 a la fecha se han creado por parte del Gobierno Federal, diversos organismos y documentos cuya finalidad ha sido la creación de nuevas empresas, y a su vez la generación de más y mejores empleos.

En el municipio de Hermosillo, Sonora, Existen cinco incubadoras de negocios con reconocimiento de la Secretaria de Economía (SE) en los tres diferentes tipos de tecnología (Tradicional, intermedia, y alta tecnología) con las cuales se ha celebrado un Convenio de Colaboradores para establecer el Sistema Municipal de Incubación de Empresas. Pretendiendo con ella, fomentar a todo nivel el emprendedurismo en Hermosillo, Sonora; Con el objetivo de ayudar a convertir las ideas innovadoras de 
Año 13.

Revista de Investigación

Núm. 33

Académica sin Frontera

ISSN: 2007-8870

https://revistainvestigacionacademicasinfrontera.unison.mx/index.php/RDIASF

Recibido el 14 de abril de 2020. Dictaminado mediante arbitraje favorablemente 9 de julio de 2020 .

negocios, en empresas exitosas, mediante la aplicación profesional de procesos incubación; elevar el valor social de la comunidad de la actividad emprendedora y; mejorar la competitividad de las incubadoras.

\section{Unidades de incubadoras en Hermosillo.}

\begin{tabular}{|c|c|c|c|c|c|c|}
\hline $\begin{array}{l}\text { NOMBRE DE LA } \\
\text { INCUBADORA }\end{array}$ & $\begin{array}{l}\text { TIPO DE } \\
\text { INCUBADORA }\end{array}$ & $\begin{array}{c}\text { LAD } \\
\mathrm{A}\end{array}$ & $\begin{array}{c}\text { TELEFON } \\
\mathrm{O}\end{array}$ & $\begin{array}{c}\text { ESTAD } \\
\mathrm{O}\end{array}$ & MUNICIPIO & CORREO ELECTRONICO \\
\hline $\begin{array}{l}\text { INCUBADORA DE } \\
\text { EMPRESAS DEL } \\
\text { ITESM, CAMPUS } \\
\text { SONORA NORTE }\end{array}$ & $\begin{array}{l}\text { TECNOLIGÍA } \\
\text { INTERMEDIA }\end{array}$ & 662 & $\begin{array}{l}2591000 \\
\text { EXT. } 2321\end{array}$ & $\begin{array}{c}\text { SONOR } \\
\text { A }\end{array}$ & $\begin{array}{l}\text { HERMOSILL } \\
\text { O }\end{array}$ & leoreyes@itesm.mx \\
\hline $\begin{array}{l}\text { INSTITUTI } \\
\text { SONORENSE DE LA } \\
\text { JUVENTUD (CEDE) }\end{array}$ & $\begin{array}{l}\text { TECNOLIGÍA } \\
\text { INTERMEDIA }\end{array}$ & 662 & $\begin{array}{l}2131013 \\
2130923 \\
2130933\end{array}$ & $\begin{array}{l}\text { SONOR } \\
\text { A }\end{array}$ & $\begin{array}{l}\text { HERMOSILL } \\
\text { O }\end{array}$ & daniela vermon@hotmal.com \\
\hline $\begin{array}{l}\text { EMPRESER } \\
\text { SONORA }\end{array}$ & $\begin{array}{c}\text { NEGOCIOS } \\
\text { INTERNACIONAL } \\
\text { ES }\end{array}$ & 662 & 2131469 & $\begin{array}{c}\text { SONOR } \\
\text { A }\end{array}$ & $\begin{array}{l}\text { HERMOSILL } \\
\text { O }\end{array}$ & mlohr@empreser.org \\
\hline $\begin{array}{l}\text { PROGRAMA } \\
\text { INSTITUCIONAL DE } \\
\text { TRANSFERENCIA } \\
\text { DE TECNOLOGIA } \\
\text { DE LA } \\
\text { UNIVERSIDAD DE } \\
\text { SONORA }\end{array}$ & $\begin{array}{l}\text { TECNOLIGÍA } \\
\text { INTERMEDIA }\end{array}$ & 662 & 2592277 & $\begin{array}{c}\text { SONOR } \\
\text { A }\end{array}$ & $\begin{array}{l}\text { HERMOSILL } \\
\text { O }\end{array}$ & txtec@txtec.uson.mx \\
\hline $\begin{array}{l}\text { UNIVERSIDAD } \\
\text { TECNOLOGICA DE } \\
\text { HERMOSILLO }\end{array}$ & $\begin{array}{l}\text { TECNOLIGÍA } \\
\text { INTERMEDIA }\end{array}$ & 662 & $\begin{array}{l}251-1100 \\
\text { AL } 04 \\
\text { EXT. } 132\end{array}$ & $\begin{array}{l}\text { SONOR } \\
\text { A }\end{array}$ & $\begin{array}{l}\text { HERMOSILL } \\
\text { O }\end{array}$ & $\underline{\text { vinculacion@uthermosillo.edu. }}$ \\
\hline
\end{tabular}

Fuente: Elaboración propia a partir del directorio de incubadoras de la Secretaria de Economía.

\section{Emprendimiento}

La palabra "emprendimiento" se deriva del término entrepreneur, fue introducido a la literatura económica por primera vez en los inicios del siglo XVIII por el economista francés Richard Cantillo. Su aporte ha sido verdaderamente relevante 
Año 13.

Revista de Investigación

Núm. 33

Académica sin Frontera

https://revistainvestigacionacademicasinfrontera.unison.mx/index.php/RDIASF

Recibido el 14 de abril de 2020. Dictaminado mediante arbitraje favorablemente 9 de julio de 2020.

para comenzar a comprender el concepto de emprendedor y el rol que juega el emprendimiento en la economía (Castillo, 1999).

Las características del emprendimiento se distinguen del resto de las personas, las características que poseen los emprendedores son los factores motivacionales que engloban la necesidad de logro, necesidad de reconocimiento, necesidad y desarrollo personal, percepción del beneficio económico, necesidad de independencia. En cuanto a las características personales habla de la iniciativa personal, capacidad de decisión, aceptación de riesgos, orientación hacia la oportunidad, estabilidad, emocional/autocontrol, responsabilidad personal, así como ser individualista y optimista. Las características intelectuales, los emprendedores poseen la flexibilidad, creatividad, imaginación, e innovación, planeación y seguimiento sistemático de resultado, visión comprensiva de los problemas, así como la capacidad de resolver problemas y planificación con límite de tiempo (Alcaraz, 2011).

\section{Emprendedor}

Emprendedor es una persona que posee necesidades psicológicas básicas, como todo ser humano, una de ellas es la necesidad de logro, necesidad de interactuar con los demás, necesidad de poder, necesidad de independencia, necesidad de

dominio de su medio, y necesidad de crear estas determina sus aptitudes y actuaciones (Alcaraz, 2011). 
Año 13.

Revista de Investigación

Núm. 33

Académica sin Frontera

https://revistainvestigacionacademicasinfrontera.unison.mx/index.php/RDIASF

Recibido el 14 de abril de 2020. Dictaminado mediante arbitraje favorablemente 9 de julio de 2020.

\section{Tipos de emprendedor}

Los distintos tipos de emprendedores se clasifican en cinco personalidades:

1.- El Emprendedor Administrativo.

Utiliza la investigación y el desarrollo para llevar nuevas investigaciones y perfeccionar las distintas formas de llevar acabo las actividades.

2.- El Emprendedor Oportunista.

El emprendedor oportunista investiga frecuentemente las oportunidades que se pueden presentar.

3.- El Emprendedor Adquisitivo.

Se mantiene continuamente en innovación, eso le permite mejora sus actitudes y crecer como un mejor emprendedor.

4.- El Emprendedor Incubador.

En su necesidad de crecer crea unidades independientes, que se convienen en negocios nuevos.

5.- El emprendedor Imitador.

Lleva acabo procesos de innovación con ayuda de elementos básicos ya existentes, mejorando cada uno de sus elementos básicos ya existentes, mejorando cada uno de sus elementos (Alcaraz, 2011).

\section{Habilidades y destrezas emprendedoras}

Comenta la habilidad emprendedora como el potencial que posee un individuo comenta que son un equipo de capacidades y conocimientos anhelados que una persona de vería de tener para llevar acabo las actividades pretendidas, esto ayuda a establecer la contraste entre profesionales de éxito y el resto (Rockefeller, 2006). 
Año 13.

Revista de Investigación

Núm. 33

Académica sin Frontera

https://revistainvestigacionacademicasinfrontera.unison.mx/index.php/RDIASF

Recibido el 14 de abril de 2020. Dictaminado mediante arbitraje favorablemente 9 de julio de 2020.

Las destrezas se definen cono la capacidad o habilidad para llevar a cabo alguna tarea de forma eficiente y eficaz manejando culturas teóricas y prácticas, además menciona las destrezas como táctica o técnica con la que es apto de llevar acabo alguna actividad o trabajo (Sánchez, 2014).

\section{Habilidades y destrezas del emprendedor según varios autores.}

\begin{tabular}{|l|l|}
\hline \multicolumn{1}{|c|}{ Habilidades emprendedoras } & \multicolumn{1}{c|}{ Destrezas emprendedoras } \\
\hline Dirigir & Identificar oportunidades \\
\hline Innovar & Proponer nuevos proyectos \\
\hline Negociar & $\begin{array}{l}\text { Organizar los recursos necesarios para ponerlos en } \\
\text { marcha }\end{array}$ \\
\hline Trabajo en equipo & Dominio del lenguaje para la expresión de sus ideas \\
\hline Iniciativa & Creatividad \\
\hline Decisión & Autoconciencia \\
\hline Adaptación a los cambios & Sensibilidad para captar cambios \\
\hline Competitividad & Fortaleza para vencer miedo al fracaso y al riesgo \\
\hline Habilidades Organizativas y de Coordinación & Mentalidad proactiva \\
\hline Capacidad de Trabajo & Capacidad de creación \\
\hline Creativo & Planificación \\
\hline Asumir riesgos & Eficiencia \\
\hline Desarrollo de liderazgo & Eficaz \\
\hline Independencia y Auto confianza & Capaz de entregar calidad \\
\hline Visión y compromiso Social & Intuición \\
\hline Habilidad para delegar & Capacidad de negociación \\
\hline Capacidad de Coordinación & Inteligencia emocional \\
\hline
\end{tabular}

El fenómeno emprendedor se ha considerado en los últimos años como un factor de desarrollo económico y que busca un desarrollo social y la creación de nuevas empresas, a través de la creación de nuevos productos o servicios que no han 
Revista de Investigación

Núm. 33

Académica sin Frontera

https://revistainvestigacionacademicasinfrontera.unison.mx/index.php/RDIASF

Recibido el 14 de abril de 2020. Dictaminado mediante arbitraje favorablemente 9 de julio de 2020.

existido hasta el momento de su creación. Se considera que los emprendedores contribuyen con los procesos en donde una persona transforma recursos, materiales y trabajo, asumiendo riesgos y por ende generando riqueza a través de las utilidades que genera la nueva organización productiva.

Por ello la iniciativa empresarial la define Hisrich como el "Proceso de crear algo nuevo con valor, dedicando el tiempo y el esfuerzo necesarios, asumiendo los correspondientes riesgos financieros, psicológicos y sociales, y obteniendo las recompensas resultantes de satisfacción e independencia económica y personal" (Hisrich, Peters, \& Shepherd, 2005) lo mencionado anteriormente refleja que las personas requieren de mucha decisión para asumir los riesgos que implica sacrificar los recursos financieros, materiales y humanos para generar una nueva empresa.

Las personas que deciden emprender tienen determinadas características o conductas que los caracterizan tal y como lo menciona Leiva "algunas de estas características pueden ser capacidad de planeación (fijar metas), manejo de contactos, comunicación efectiva, búsqueda de información, creatividad, trabajo en equipo, toma de decisiones y liderazgo" (Leiva Bonilla, 2007), por lo antes mencionado se encuentra que las características que poseen los emprendedores son semejantes aunque las circunstancias que rodean a cada persona suelen desarrollar algunas características más que otras interviniendo entonces un nuevo elemento que son las motivaciones que orillan a los emprendedores a generar una nueva empresa.

Como se mencionó anteriormente las condiciones de cada uno de los emprendedores es diferente y es por ello que cada uno tiene diferentes 
Año 13.

Revista de Investigación

Núm. 33

Académica sin Frontera

https://revistainvestigacionacademicasinfrontera.unison.mx/index.php/RDIASF

Recibido el 14 de abril de 2020. Dictaminado mediante arbitraje favorablemente 9 de julio de 2020 .

motivaciones para decidir emprender por necesidad o por oportunidad y según "un emprendedor por necesidad es aquel que se encuentra inmerso en el proceso emprendedor por no tener una mejor opción en el mercado laboral; mientras que un emprendedor por oportunidad es aquel que escoge crear una empresa basándose en la percepción de que existe una oportunidad de negocio no aprovechada o aprovechada de forma incompleta por las empresas existentes", (Fernández Laviada, 2015) aunque se debe considerar que en ocasiones los que emprenden por necesidad, tienden a abandonar su empresa cuando logran conseguir un empleo con ingresos fijos.

\section{Global Entrepreneurship Monitor}

A nivel internacional existe un estudio denominado Global Entrepreneurship Monitor que inicia desde 1997 que fue impulsado por la Universidad Babson College de los Estados Unidos y la Universidad London School of Business del Reino Unido y tiene el objetivo de medir el emprendimiento en diferentes países y observar en qué grado esta actividad afecta la tasa de crecimiento económico, adicionalmente busca identificar los factores que impulsan o limitan la actividad emprendedora, a través de las diversas políticas públicas que se establecen para generar una percepción positiva hacia la creación de empresas en los emprendedores.

Este estudio según (Querejazu, 2015) considera que "En estos 16 años de trabajo continuo, el GEM ha medido el emprendimiento en más de 100 países, que representan a todas las regiones geográficas y a los diferentes niveles económicos existentes en el Globo. Desde el año 2008, el GEM cubre los tres tipos de economías de acuerdo con la clasificación del Foro Económico Mundial basada en 
Año 13.

Revista de Investigación

Núm. 33

Académica sin Frontera

https://revistainvestigacionacademicasinfrontera.unison.mx/index.php/RDIASF

Recibido el 14 de abril de 2020. Dictaminado mediante arbitraje favorablemente 9 de julio de 2020 .

la tipología de desarrollo de Michael Porter (Porter, 2002)", como se observa este estudio ha tenido bastante presencia a nivel internacional y ha generado información relevante para conocer el fenómeno emprendedor.

\section{Marco Conceptual GEM}

Para realizar la presente investigación se tomará como referencia el Marco Conceptual del GEM, toda vez que desde su creación ha buscado identificar interdependencia entre el emprendimiento y el desarrollo económico de un país, considerando que la creación de empresas es fundamental para la generación de nuevos empleos tal y como lo menciona Reynolds que indica "Cualquier intento de creación de nuevos negocios o empresas, tales como el autoempleo, una nueva empresa, o la expansión de un negocio existente, por un individuo, un equipo de individuos, o un negocio establecido" (Reynolds, 1999) lo anterior refleja cómo se ha construido el Marco Conceptual del GEM y se muestra a continuación:

A continuación se describen los diferentes componentes que integran el Marco Conceptual del GEM (Singer, 2015).

Contexto Social, Cultural, Político: En este componente se define el uso de los doce pilares del Foro Económico Mundial para perfilar las fases de desarrollo económico durante el levantamiento de datos sobre la competitividad y por ello se requiere analizar cuál es el diseño de Políticas Públicas para construir un ecosistema de apoyo para estimular un comportamiento emprendedor en las personas. 
Año 13.

Revista de Investigación

Núm. 33

Académica sin Frontera

https://revistainvestigacionacademicasinfrontera.unison.mx/index.php/RDIASF

Recibido el 14 de abril de 2020. Dictaminado mediante arbitraje favorablemente 9 de julio de 2020 .

Valores Sociales hacia la Iniciativa Emprendedora: En este componente se considera como la sociedad aprecia el emprendimiento como una alternativa de carrera, debido a que un buen estatus económico por parte de los empresarios y la adecuada difusión de los medios de comunicación, pueden contribuir a fomentar y desarrollar una cultura emprendedora nacional.

Atributos Individuales: En este componente se buscan identificar factores demográficos tales como el sexo, edad y ubicación geográfica; factores psicológicos como las capacidades percibidas, oportunidades percibidas y temor al fracaso y por último los aspectos motivacionales que impulsan el emprendedurismo que puede ser por necesidad o por oportunidad.

Actividad Emprendedora: En este componente se considera el ciclo de vida de las empresas que se pueden considerar como nacientes nuevos, negocios establecidos y cierre de negocios y los tipos de actividad son de alto crecimiento, innovación e internacionalización y el sector de la actividad son la actividad emprendedora temprana, la Actividad empresarial social y la Actividad emprendedora del Empleado.

Como se observan son varios los componentes que integran el Marco Conceptual del GEM y que influyen de manera importante en el quehacer de los emprendedores.

En esta investigación se desarrollan dos instrumentos que permitan identificar las condiciones existentes para medir el fenómeno emprendedor e identificar las características de los emprendedores en Hermosillo, Sonora, considerando la 
Revista de Investigación

Año 13.

Académica sin Frontera

Núm. 33

ISSN: 2007-8870

https://revistainvestigacionacademicasinfrontera.unison.mx/index.php/RDIASF

Recibido el 14 de abril de 2020. Dictaminado mediante arbitraje favorablemente 9 de julio de 2020 .

segmentación de acuerdo a las condiciones productivas, económicas, sociales y culturales.

Para este estudio se utilizará, los instrumentos del modelo GEM (Cuestionarios), para la recolección de los datos y su posterior análisis.

A continuación, se presentan las dimensiones y los ítems que integra el instrumento que se aplicará a expertos en el tema del Emprendedurismo.

\section{Instrumento para Expertos}

I. Financiamiento

I.1. Hay suficiente financiamiento disponible a través de la salida a bolsa para las empresas nuevas y en crecimiento.

I.2. Existe una oferta suficiente de capital de riesgo para las empresas nuevas y en crecimiento.

I.3. Hay suficiente financiamiento disponible procedente de inversionistas privados informales (distintos de los fundadores) para las empresas nuevas y en crecimiento.

I.4. Existen suficientes subsidios públicos disponibles para las empresas nuevas y en crecimiento.

1.5. Hay suficientes medios de financiamiento procedentes de entidades financieras privadas para las empresas.

I.6.Existe suficiente capital propio de los emprendedores para financiar las empresas nuevas y en crecimiento.

II. Políticas Gubernamentales

II.1. Levar a cabo los trámites burocráticos y obtener las licencias que marca la ley para desarrollar empresas nuevas y en crecimiento NO representan una especial dificultad.

II.2. Los impuestos, tasas y otras regulaciones gubernamentales son aplicadas a las empresas nuevas y en crecimiento de una manera predecible y coherente. II.3Los impuestos NO contribuyen una barrera para crear nuevas empresas e impulsar el crecimiento de la empresa en general. 
Revista de Investigación

Año 13.

Académica sin Frontera

Núm. 33

ISSN: 2007-8870

https://revistainvestigacionacademicasinfrontera.unison.mx/index.php/RDIASF

Recibido el 14 de abril de 2020. Dictaminado mediante arbitraje favorablemente 9 de julio de 2020 .

II.4. Las nuevas empresas pueden realizar todos los trámites administrativos y legales (obtención de licencias y permisos) en aproximadamente una semana.

II.5 El apoyo a empresas nuevas y en crecimiento es una prioridad en la política del gobierno estatal.

II.6. El apoyo a empresas nuevas y en crecimiento es una prioridad en la política del gobierno federal.

II.7. La política gubernamental favorece claramente a las empresas de nueva creación (por ejemplo, en las licitaciones o aprovisionamiento públicos)

III. Programas Gubernamentales

III.1. Los programas gubernamentales que apoyan a las empresas nuevas y en crecimiento son efectivos.

III.2. Casi todo el que necesita ayuda de un programa de gobierno para crear o hacer crecer una empresa puede encontrar alguno que se ajuste a sus necesidades.

III.3. Los profesionales que trabajan en las agencias gubernamentales de apoyo a la creación y al crecimiento de nuevas empresas son competentes y eficaces.

III.4. Existe un número adecuado de programas que fomentan la creación y el crecimiento de nuevas empresas.

III.5. Los parques científicos e incubadoras aportan un apoyo efectivo a las empresas nuevas y en crecimiento.

III.6. Puede obtenerse información sobre una amplia gama de programas gubernamentales para empresas nuevas y en crecimiento contactando con una sola dependencia (ventanilla única)

IV. Educación y Formación.

IV.1. Los sistemas de formación profesional y capacitación continua proporcionan una preparación adecuada y de calidad para la creación de nuevas empresas y el crecimiento de las establecidas.

IV.2. La formación en administración, dirección y gestión de empresas proporciona una preparación adecuada y de calidad para la creación de nuevas empresas y el crecimiento de las establecidas.

IV.3. Las universidades y centros de enseñanza superior proporcionan una preparación adecuada y de calidad para la creación de nuevas empresas y el crecimiento de las establecidas. 
Año 13.

Revista de Investigación

Académica sin Frontera

Núm. 33

ISSN: 2007-8870

https://revistainvestigacionacademicasinfrontera.unison.mx/index.php/RDIASF

Recibido el 14 de abril de 2020. Dictaminado mediante arbitraje favorablemente 9 de julio de 2020 .

IV.4. La educación primaria y secundaria dedica suficiente atención al espíritu empresarial y a la creación de empresas.

IV.5. La educación primaria y secundaria aporta conocimientos suficientes y adecuados acerca de los principios de una economía de mercado.

IV.6. La educación primaria y secundaria estimula la creatividad, la autosuficiencia y la iniciativa personal

V. Transferencia de Investigación y Desarrollo

V.1. Existe el apoyo suficiente para que los ingenieros y científicos puedan explotar económicamente sus ideas a través de la creación de nuevas empresas.

V.2. La ciencia y la tecnología permiten la creación de empresas de base tecnológica competitivas en el nivel global al menos en un campo concreto.

V.3. Los subsidios y apoyos gubernamentales a empresas nuevas y en crecimiento para adquirir nuevas tecnologías son suficientes y adecuados.

V.4. Las empresas nuevas y en crecimiento se pueden costear las últimas tecnologías.

V.5. Las empresas nuevas y en crecimiento tienen el mismo acceso a las nuevas investigaciones y tecnologías que las ya establecidas.

V.6. Las nuevas tecnologías, la ciencia, y otros conocimientos se transfieren de forma eficiente desde las universidades y los centros de investigación públicos a las empresas nuevas y en crecimiento.

VI. Infraestructura Comercial

VI.1. Las empresas nuevas y en crecimiento tienen fácil acceso a buenos servicios bancarios (apertura de cuentas corrientes, transacciones comerciales con el extranjero, cartas de crédito y similares).

VI.2. Las empresas nuevas y en crecimiento tienen fácil acceso a un buen asesoramiento legal, laboral, contable y fiscal.

VI.3. Las empresas nuevas y en crecimiento tienen fácil acceso a buenos proveedores, consultores y subcontratista.

VI.4. Las empresas nuevas y en crecimiento pueden asumir el costo de subcontratista, proveedores y consultores.

VI.5. Existen suficientes proveedores, consultores y subcontratistas para dar soporte a las empresas nuevas y en crecimiento.

VII. Apertura del Mercado Interno

VII.1. La legislación antimonopolio es efectiva y se hace cumplir. 
Año 13.

Revista de Investigación

Académica sin Frontera

Núm. 33

ISSN: 2007-8870

https://revistainvestigacionacademicasinfrontera.unison.mx/index.php/RDIASF

Recibido el 14 de abril de 2020. Dictaminado mediante arbitraje favorablemente 9 de julio de 2020 .

VII.2. Las empresas nuevas y en crecimiento pueden entrar en nuevos mercados sin ser bloqueadas de forma desleal por las empresas establecidas.

VII.3. Las empresas nuevas y en crecimiento pueden asumir los costos de entrada al mercado.

VII.4. Las empresas nuevas y en crecimiento pueden entrar fácilmente en nuevos mercados.

VII.5. Los mercados de bienes y servicios para empresas cambian drásticamente de un ejercicio a otro.

VII.6. Los mercados de bienes y servicios de consumo cambian drásticamente de un ejercicio a otro.

\section{Acceso a Infraestructura Física}

VIII.1. Una nueva empresa o en crecimiento puede tener acceso a los servicios básicos (gas, agua, electricidad, alcantarillado, etc.) en aproximadamente un mes.

VIII.2. Las empresas de nueva creación y en crecimiento pueden afrontar los costos de los servicios básicos (gas, agua, electricidad, etc.).

VIII.3. Una empresa nueva o en crecimiento puede proveerse de servicios de comunicaciones en aproximadamente una semana (teléfono, internet, etc.)

VIII.4. No es excesivamente caro para una empresa nueva o en crecimiento acceder a sistemas de comunicación (teléfono, internet, etc.).

VIII.5. La infraestructura física (carreteras, telecomunicaciones, etc.) proporcionan un buen apoyo para las empresas nuevas y en crecimiento

\section{Normas Sociales y Culturales}

IX.1. Las normas sociales y culturales enfatizan que ha de ser el individuo (más que la comunidad) el responsable de gestionar su propia vida.

IX.2. Las normas sociales y culturales estimulan la creatividad y la innovación.

IX.3. Las normas sociales y culturales estimulan la toma de riesgo empresarial.

IX.4. Las normas sociales y culturales enfatizan la autosuficiencia, la autonomía y la iniciativa personal.

IX.5. Las normas sociales y culturales apoyan y valoran el éxito individual se consiguió a través del esfuerzo personal. 
Año 13.

Revista de Investigación

Núm. 33

Académica sin Frontera

https://revistainvestigacionacademicasinfrontera.unison.mx/index.php/RDIASF

Recibido el 14 de abril de 2020. Dictaminado mediante arbitraje favorablemente 9 de julio de 2020.

\section{Metodología}

El presente trabajo de investigación se realizó con un enfoque cuantitativo y de corte transversal, se apoyó en el resultado obtenido en el instrumento de aplicación a expertos (Incubadoras y otros), en Hermosillo,Sonora.

La muestra fue por conveniencia y se aplicaron 8 instrumentos, a cinco incubadoras y a tres expertos, una vez aplicados los instrumentos de medición se capturaron para su procesamiento estadístico en el softwere estadístico IBM.SPSS. Statistics.v21. el cual nos arrojó un Alfa de Cronbach de .962, y se realizó el estadístico descriptivo e inferencial.

Escala utilizada en el instrumento de investigación.

1.- Es completamente cierto, 2.- Es más bien cierto, 3.- Es ni cierto ni falso, 4.- Es más bien falso, 5.- Es totalmente falso.

\section{Objetivo}

a) Conocer el emprendimiento desde el punto de vista de los expertos en Sonora

b) Proponer algunas estrategias para fomentar el espíritu emprendedor en los diferentes sectores en la ciudad de Hermosillo, Sonora.

\section{Preguntas de investigación}

¿Cómo se puede generar la cultura emprendedora que fomente la creación de nuevas empresas? 
Año 13.

Revista de Investigación

Núm. 33

Académica sin Frontera

https://revistainvestigacionacademicasinfrontera.unison.mx/index.php/RDIASF

Recibido el 14 de abril de 2020. Dictaminado mediante arbitraje favorablemente 9 de julio de 2020.

\section{La presente investigación tiene una importancia relevante.}

- Permitir conocer un panorama desde la perspectiva de los expertos de acuerdo con las condiciones económicas, políticas y sociales que prevalecen en Hermosillo, Sonora de acuerdo con las vocaciones productivas de la zona.

\section{Alcances:}

- El proyecto está enfocado al estudio del emprendimiento en la ciudad de Hermosillo, Sonora.

- El emprendimiento según los expertos, que para este caso se considerarán a las incubadoras y otros profesionales (como expertos)

\section{Limitaciones:}

- Se decidió tomar en consideración solo incubadoras y expertos.

\section{Análisis de resultados}

Sociodemográficos.

La edad de los encuestados muestra que un $37.5 \%$ oscila entre los 18 y 35 años, y un $62.5 \%$ oscila entre los 36 a 59 años. El género, el 50\% son Hombres y el $50 \%$ son mujeres. De estos el $25 \%$ estudio una licenciatura y el $75 \%$ un posgrado. El área de conocimiento, el $62 \%$ de ingeniería y el $25 \%$ económico administrativo y el $12 \%$ no contesto y el lugar de trabajo mostro que son del C-EMPREN-DHE son el $12.5 \%$, de NACE Inc. Sonora A.C el 12.5\%, de la secretaria de economía el $25.0 \%$, del Tec. de Monterrey $12.5 \%$, de la Universidad estatal de Sonora el $12.5 \%$, de la Universidad de Sonora el $12.5 \%$, y el $12.5 \%$ no contesto. 
Revista de Investigación

Núm. 33

Académica sin Frontera

ISSN: 2007-8870

https://revistainvestigacionacademicasinfrontera.unison.mx/index.php/RDIASF

Recibido el 14 de abril de 2020. Dictaminado mediante arbitraje favorablemente 9 de julio de 2020 .

\begin{tabular}{|c|c|c|c|c|c|}
\hline \multirow{2}{*}{ FINANCIAMIENTO } & \multicolumn{5}{|c|}{ PORCENTAJE } \\
\hline & 1 & 2 & 3 & 4 & 5 \\
\hline $\begin{array}{l}\text { Hay suficiente financiamiento disponible a través de la salida a bolsa } \\
\text { para las empresas nuevas y en crecimiento. }\end{array}$ & & 12.5 & 37.5 & 25.0 & 25.0 \\
\hline $\begin{array}{l}\text { Existe una oferta suficiente de capital de riesgo para las empresas } \\
\text { nuevas y en crecimiento. }\end{array}$ & & & 25.0 & 50.0 & 25.0 \\
\hline $\begin{array}{l}\text { Hay suficiente financiamiento disponible procedente de } \\
\text { inversionistas privados informales (distintos de los fundadores) para } \\
\text { las empresas nuevas y en crecimiento. }\end{array}$ & & & 37.5 & & 62.5 \\
\hline $\begin{array}{l}\text { Existen suficientes subsidios públicos disponibles para las empresas } \\
\text { nuevas y en crecimiento. }\end{array}$ & & & 62.5 & 25.0 & 12.5 \\
\hline $\begin{array}{l}\text { Hay suficientes medios de financiamiento procedentes de entidades } \\
\text { financieras privadas para las empresas. }\end{array}$ & & 12.5 & 37.5 & 25.0 & 25.0 \\
\hline $\begin{array}{l}\text { Existe suficiente capital propio de los emprendedores para financiar } \\
\text { las empresas nuevas y en crecimiento. }\end{array}$ & & & 25.0 & 62.5 & 12.5 \\
\hline
\end{tabular}

La dimensión de financiamiento presenta resultados que demuestran según la opinión de los expertos no hay y no existen la disposición de recursos para las empresas Pymes de nueva creación y las que se encuentran en crecimiento por parte de la iniciativa privada, por ende, tanto los nuevos emprendedores, así como los consolidados cuenta con un panorama desfavorable para emprender y crecer.

\begin{tabular}{|c|c|c|c|c|c|}
\hline \multirow[t]{2}{*}{ POLÍTICAS GUBERNAMENTALES } & \multicolumn{5}{|c|}{ PPRCENTAJE } \\
\hline & 1 & 2 & 3 & 4 & 5 \\
\hline $\begin{array}{l}\text { Llevar a cabo los trámites burocráticos y obtener las licencias que } \\
\text { marca la ley para desarrollar empresas nuevas y en crecimiento } \\
\text { NO representan una especial dificultad. }\end{array}$ & & 12.5 & 37.5 & 37.5 & 12.5 \\
\hline $\begin{array}{l}\text { Los impuestos, tasas y otras regulaciones gubernamentales son } \\
\text { aplicados a las empresas nuevas y en crecimiento de una manera } \\
\text { predecible y coherente. }\end{array}$ & & 25.0 & 37.5 & 25.0 & 12.5 \\
\hline $\begin{array}{l}\text { Los impuestos NO contribuyen una barrera para crear nuevas } \\
\text { empresas e impulsar el crecimiento de la empresa en general. }\end{array}$ & & 12.5 & 37.5 & 37.5 & 12.5 \\
\hline
\end{tabular}


Año 13.

Revista de Investigación

Núm. 33

Académica sin Frontera

ISSN: 2007-8870

https://revistainvestigacionacademicasinfrontera.unison.mx/index.php/RDIASF

Recibido el 14 de abril de 2020. Dictaminado mediante arbitraje favorablemente 9 de julio de 2020.

\begin{tabular}{|c|c|c|c|c|c|}
\hline $\begin{array}{l}\text { Las nuevas empresas pueden realizar todos los trámites } \\
\text { administrativos y legales (obtención de licencias y permisos) en } \\
\text { aproximadamente una semana. }\end{array}$ & & & 25.0 & 37.5 & 37.5 \\
\hline $\begin{array}{l}\text { El apoyo a empresas nuevas y en crecimiento es una prioridad en } \\
\text { la política del gobierno estatal. }\end{array}$ & 12.5 & 25.0 & 25.0 & 12.5 & 25.0 \\
\hline $\begin{array}{l}\text { El apoyo a empresas nuevas y en crecimiento es una prioridad en } \\
\text { la política del gobierno federal. }\end{array}$ & 12.5 & 50.0 & 12.5 & & 25.0 \\
\hline $\begin{array}{l}\text { La política gubernamental favorece claramente a las empresas de } \\
\text { nueva creación (por ejemplo, en las licitaciones o } \\
\text { aprovisionamiento públicos). }\end{array}$ & & 12.5 & 25.0 & 50.0 & 12.5 \\
\hline
\end{tabular}

La dimensión de políticas gubernamentales presenta resultados que según los expertos por parte del gobierno no existen política claras o subsidio que apoye a las Pymes de nueva creación y en crecimientos, por ende, las políticas gubernamentales se consideran ausentes para el apoyo a los emprendedores que se deciden a aperturar una nueva empresa y lograr sus objetivos personales.

\begin{tabular}{|c|c|c|c|c|c|}
\hline \multirow[t]{2}{*}{ PROGRAMAS GUBERNAMENTALES } & \multicolumn{5}{|c|}{ PORCENTAJES } \\
\hline & 1 & 2 & 3 & 4 & 5 \\
\hline $\begin{array}{l}\text { Los programas gubernamentales que apoyan a las empresas } \\
\text { nuevas y en crecimiento son efectivos. }\end{array}$ & & 25.0 & 12.5 & 50.0 & 12.5 \\
\hline $\begin{array}{l}\text { Casi todo el que necesita ayuda de un programa de gobierno para } \\
\text { crear o hacer crecer una empresa puede encontrar alguno que se } \\
\text { ajuste a sus necesidades. }\end{array}$ & & 12.5 & 25.0 & 37.5 & 25.0 \\
\hline $\begin{array}{l}\text { Los profesionales que trabajan en las agencias gubernamentales } \\
\text { de apoyo a la creación y al crecimiento de nuevas empresas son } \\
\text { competentes y eficaces. }\end{array}$ & & 25.0 & 37.5 & 25.0 & 12.5 \\
\hline $\begin{array}{l}\text { Existe un número adecuado de programas que fomentan la } \\
\text { creación y el crecimiento de nuevas empresas. }\end{array}$ & & & 62.5 & 25.0 & 12.5 \\
\hline $\begin{array}{l}\text { Los parques científicos e incubadoras aportan un apoyo efectivo a } \\
\text { las empresas nuevas y en crecimiento. }\end{array}$ & & 37.5 & 37.5 & 25.0 & \\
\hline $\begin{array}{l}\text { Puede obtenerse información sobre una amplia gama de } \\
\text { programas gubernamentales para empresas nuevas y en } \\
\text { crecimiento contactando con una sola dependencia (ventanilla } \\
\text { única). }\end{array}$ & 12.5 & & 25.0 & 25.0 & 37.5 \\
\hline
\end{tabular}

La dimensión de programas gubernamentales presenta resultados que a opinión de los expertos por parte del gobierno no existen programas que apoye a las Pymes de nueva creación y en crecimientos, por ende, la carencia de programas 
Año 13.

Revista de Investigación

Núm. 33

Académica sin Frontera

ISSN: 2007-8870

https://revistainvestigacionacademicasinfrontera.unison.mx/index.php/RDIASF

Recibido el 14 de abril de 2020. Dictaminado mediante arbitraje favorablemente 9 de julio de 2020 .

gubernamentales representa un vacío el cual los emprendedores deben de superar para poder lograr sus objetivos personales, empero, los parques científicos e incubadoras aportan un apoyo efectivo a las empresas nuevas y en crecimiento.

\begin{tabular}{|c|c|c|c|c|c|}
\hline \multirow[t]{2}{*}{ EDUCACIÓN Y FORMACIÓN } & \multicolumn{5}{|c|}{ PORCENTAJES } \\
\hline & 1 & 2 & 3 & 4 & 5 \\
\hline $\begin{array}{l}\text { Los sistemas de formación profesional y capacitación continua } \\
\text { proporcionan una preparación adecuada y de calidad para la } \\
\text { creación de nuevas empresas y el crecimiento de las establecidas. }\end{array}$ & 12.5 & 37.5 & 25.0 & 25.0 & \\
\hline $\begin{array}{l}\text { L+O4:V6a formación en administración, dirección y gestión de } \\
\text { empresas, proporciona una preparación adecuada y de calidad } \\
\text { para la creación de nuevas empresas y el crecimiento de las } \\
\text { establecidas. }\end{array}$ & 12.5 & 37.5 & 50.0 & & \\
\hline $\begin{array}{l}\text { Las universidades y centros de enseñanza superior proporcionan } \\
\text { una preparación adecuada y de calidad para la creación de nuevas } \\
\text { empresas y el crecimiento de las establecidas. }\end{array}$ & & 25.0 & 62.5 & 12.5 & \\
\hline $\begin{array}{l}\text { La educación primaria y secundaria dedica suficiente atención al } \\
\text { espíritu empresarial y a la creación de empresas. }\end{array}$ & & & 25.0 & 37.5 & 37.5 \\
\hline $\begin{array}{l}\text { La educación primaria y secundaria aporta conocimientos } \\
\text { suficientes y adecuados acerca de los principios de una economía } \\
\text { de mercado. }\end{array}$ & & & 25.0 & 25.0 & 50.0 \\
\hline $\begin{array}{l}\text { La educación primaria y secundaria estimula la creatividad, la } \\
\text { autosuficiencia y la iniciativa personal }\end{array}$ & & 12.5 & 37.5 & 25.0 & 25.0 \\
\hline
\end{tabular}

La dimensión de educación y formación presenta resultados que demuestran de acuerdo a la opinión de los expertos no hay y no existen dentro del sistema educativo básico una formación de emprendedores salvo en la universidades y en aquellas áreas como la económico administrativo donde si bien se carece de la formación del perfil emprendedor si reciben conocimientos del manejo de las empresas y pero aun así la formación de emprendedores en si, no es recibida, por lo tanto la formación de emprendedores está ausente y demuestra debilidad para la apertura y crecimiento de las Pymes en Hermosillo, Sonora. 
Revista de Investigación

Núm. 33

Académica sin Frontera

ISSN: 2007-8870

https://revistainvestigacionacademicasinfrontera.unison.mx/index.php/RDIASF

Recibido el 14 de abril de 2020. Dictaminado mediante arbitraje favorablemente 9 de julio de 2020 .

\begin{tabular}{|c|c|c|c|c|c|}
\hline \multirow[t]{2}{*}{ TRANSPARENCIA DE INVESTIGACIÓN Y DESARROLLO } & \multicolumn{5}{|c|}{ PORCENTAJES } \\
\hline & 1 & 2 & 3 & 4 & 5 \\
\hline $\begin{array}{l}\text { Existe el apoyo suficiente para que los ingenieros y científicos } \\
\text { puedan explotar económicamente sus ideas a través de la creación de } \\
\text { nuevas empresas. }\end{array}$ & & & 62.5 & 25.0 & 12.5 \\
\hline $\begin{array}{l}\text { La ciencia y la tecnología permiten la creación de empresas de base } \\
\text { tecnológica competitivas en el nivel global al menos en un campo } \\
\text { concreto. }\end{array}$ & & 50.0 & 25.0 & 12.5 & 12.5 \\
\hline $\begin{array}{l}\text { Los subsidios y apoyos gubernamentales a empresas nuevas y en } \\
\text { crecimiento para adquirir nuevas tecnologías son suficientes y } \\
\text { adecuados. }\end{array}$ & & & 12.5 & 62.5 & 25.0 \\
\hline $\begin{array}{l}\text { Las empresas nuevas y en crecimiento se pueden costear las últimas } \\
\text { tecnologías. }\end{array}$ & & & & 62.5 & 37.5 \\
\hline $\begin{array}{l}\text { Las empresas nuevas y en crecimiento tienen el mismo acceso a las } \\
\text { nuevas investigaciones y tecnologías que las ya establecidas. }\end{array}$ & & & 25.0 & 37.5 & 37.5 \\
\hline $\begin{array}{l}\text { Las nuevas tecnologías, la ciencia, y otros conocimientos se } \\
\text { transfieren de forma eficiente desde las universidades y los centros } \\
\text { de investigación públicos a las empresas nuevas y en crecimiento. }\end{array}$ & & & 12.5 & 62.5 & 25.0 \\
\hline
\end{tabular}

La dimensión de transparencia de investigación y desarrollo presenta resultados que demuestran según la opinión de los expertos no hay y no existen la disposición de recursos para las empresas Pymes de nueva creación y las que se encuentran en crecimiento para la obtención de nueva tecnología, aun así, están de acuerdo que la tecnología es el medio por el cual las empresas se vuelven más competitivas y logran un crecimiento sostenido. 
Año 13.

Revista de Investigación

Núm. 33

Académica sin Frontera

ISSN: 2007-8870

https://revistainvestigacionacademicasinfrontera.unison.mx/index.php/RDIASF

Recibido el 14 de abril de 2020. Dictaminado mediante arbitraje favorablemente 9 de julio de 2020 .

\begin{tabular}{|c|c|c|c|c|c|}
\hline & 1 & 2 & 3 & 4 & 5 \\
\hline $\begin{array}{l}\text { Las empresas nuevas y en crecimiento tienen fácil acceso a } \\
\text { buenos servicios bancarios (apertura de cuentas corrientes, } \\
\text { transacciones comerciales con el extranjero, cartas de crédito y } \\
\text { similares). }\end{array}$ & 12.5 & 25.0 & 25.0 & 25.0 & 12.5 \\
\hline $\begin{array}{l}\text { Las empresas nuevas y en crecimiento tienen fácil acceso a un } \\
\text { buen asesoramiento legal, laboral, contable y fiscal. }\end{array}$ & & 37.5 & 37.5 & 12.5 & 12.5 \\
\hline $\begin{array}{l}\text { Las empresas nuevas y en crecimiento tienen fácil acceso a } \\
\text { buenos proveedores, consultores y subcontratista. }\end{array}$ & 12.5 & 25.0 & 37.5 & 12.5 & 12.5 \\
\hline $\begin{array}{l}\text { Las empresas nuevas y en crecimiento pueden asumir el costo de } \\
\text { subcontratista, proveedores y consultores. }\end{array}$ & & & 25.0 & 62.5 & 12.5 \\
\hline $\begin{array}{l}\text { Existen suficientes proveedores, consultores y subcontratistas } \\
\text { para dar soporte a las empresas nuevas y en crecimiento. }\end{array}$ & & 12.5 & 62.5 & 12.5 & 12.5 \\
\hline
\end{tabular}

La dimensión de infraestructura comercial presenta resultados que demuestran según la opinión de los expertos que hay y existen la manera de realizar operaciones con clientes o proveedores en el extranjero así como los servicios bancarios para poder realizarlos, empero se carece de expertos que los puedan asesorar en cuestiones de negocios a los emprendedores, por tal motivo la infraestructura es limitada para la creación y el crecimiento de las empresas Pymes en la Ciudad de Hermosillo, sonora.

\begin{tabular}{|c|c|c|c|c|c|}
\hline \multirow[t]{2}{*}{ APERTURA DEL MERCADO INTERNO } & \multicolumn{5}{|c|}{ PORCENTAJE } \\
\hline & 1 & 2 & 3 & 4 & 5 \\
\hline La legislación antimonopolio es efectiva y se hace cumplir. & & 25.0 & 50.0 & 12.5 & 12.5 \\
\hline $\begin{array}{l}\text { Las empresas nuevas y en crecimiento pueden entrar en nuevos } \\
\text { mercados sin ser bloqueadas de forma desleal por las empresas } \\
\text { establecidas. }\end{array}$ & & & 25.0 & 50.0 & 25.0 \\
\hline $\begin{array}{l}\text { Las empresas nuevas y en crecimiento pueden asumir los costos de } \\
\text { entrada al mercado. }\end{array}$ & & & 12.5 & 75.0 & 12.5 \\
\hline $\begin{array}{l}\text { Las empresas nuevas y en crecimiento pueden entrar fácilmente en } \\
\text { nuevos mercados. }\end{array}$ & & & 37.5 & 50.0 & 12.5 \\
\hline $\begin{array}{l}\text { Los mercados de bienes y servicios para empresas cambian } \\
\text { drásticamente de un ejercicio a otro. }\end{array}$ & & 12.5 & 87.5 & & \\
\hline $\begin{array}{l}\text { Los mercados de bienes y servicios de consumo cambian } \\
\text { drásticamente de un ejercicio a otro. }\end{array}$ & & 25.0 & 75.0 & & \\
\hline
\end{tabular}


Año 13.

Revista de Investigación

Núm. 33

Académica sin Frontera

ISSN: 2007-8870

https://revistainvestigacionacademicasinfrontera.unison.mx/index.php/RDIASF

Recibido el 14 de abril de 2020. Dictaminado mediante arbitraje favorablemente 9 de julio de 2020 .

La dimensión de apertura del mercado interno presenta resultados que indican según la respuesta de los expertos no hay y no existen la competencia perfecta de los mercados en la ciudad de Hermosillo, sonora, aparte que los nuevos emprendedores se enfrentan a un mercado cambiante lo cual se vuelve una desventaja a la hora de aperturar negocios tanto para los nuevos emprendedores como los que se encuentran en crecimiento.

\begin{tabular}{|c|c|c|c|c|c|}
\hline \multirow[t]{2}{*}{ ACCESO A INFRAESTRUCTURA FISICA } & \multicolumn{5}{|c|}{ PORCENTAJE } \\
\hline & 1 & 2 & 3 & 4 & 5 \\
\hline $\begin{array}{l}\text { Una nueva empresa o en crecimiento puede tener acceso a los } \\
\text { servicios básicos (gas, agua, electricidad, alcantarillado, etc.) en } \\
\text { aproximadamente un mes. }\end{array}$ & 37.5 & 50.0 & 12.5 & & \\
\hline $\begin{array}{l}\text { Las empresas de nueva creación y en crecimiento pueden afrontar los } \\
\text { costos de los servicios básicos (gas, agua, electricidad, etc.) }\end{array}$ & & 75.0 & 12.5 & & 12.5 \\
\hline $\begin{array}{l}\text { Una empresa nueva o en crecimiento puede proveerse de servicios de } \\
\text { comunicaciones en aproximadamente una semana (teléfono, internet, } \\
\text { etc.) }\end{array}$ & 25.0 & 62.5 & 12.5 & & \\
\hline $\begin{array}{l}\text { No es excesivamente caro para una empresa nueva o en crecimiento } \\
\text { acceder a sistemas de comunicación (teléfono, internet, etc.) }\end{array}$ & 25.0 & 62.5 & & & 12.5 \\
\hline $\begin{array}{l}\text { La infraestructura física (carreteras, telecomunicaciones, etc.) } \\
\text { proporcionan un buen apoyo para las empresas nuevas y en } \\
\text { crecimiento. }\end{array}$ & 12.5 & 37.5 & 37.5 & & 12.5 \\
\hline
\end{tabular}

La dimensión de acceso a infraestructura física presenta resultados que demuestran según la opinión de los expertos, que hay y existen los servicios básicos e infraestructura de comunicaciones al alcance de todos aquellos emprendedores que se decidan aperturar un negocio. 
Año 13.

Revista de Investigación

Académica sin Frontera

Núm. 33

ISSN: 2007-8870

https://revistainvestigacionacademicasinfrontera.unison.mx/index.php/RDIASF

Recibido el 14 de abril de 2020. Dictaminado mediante arbitraje favorablemente 9 de julio de 2020.

\begin{tabular}{|c|c|c|c|c|c|}
\hline \multirow[t]{2}{*}{ NORMAS SOCIALES Y CULTURALES } & \multicolumn{5}{|c|}{ PORCENTAJES } \\
\hline & 1 & 2 & 3 & 4 & 5 \\
\hline $\begin{array}{l}\text { Las normas sociales y culturales enfatizan que ha de ser el } \\
\text { individuo (más que la comunidad) el responsable de gestionar su } \\
\text { propia vida. }\end{array}$ & 50.0 & 12.5 & 37.5 & & \\
\hline $\begin{array}{l}\text { Las normas sociales y culturales estimulan la creatividad y la } \\
\text { innovación. }\end{array}$ & & 12.5 & 75.0 & 12.5 & \\
\hline $\begin{array}{l}\text { Las normas sociales y culturales estimulan la toma de riesgo } \\
\text { empresarial. }\end{array}$ & & 12.5 & 37.5 & 37.5 & 12.5 \\
\hline $\begin{array}{l}\text { Las normas sociales y culturales enfatizan la autosuficiencia, la } \\
\text { autonomía y la iniciativa personal. }\end{array}$ & & & 50.0 & 37.5 & 12.5 \\
\hline $\begin{array}{l}\text { Las normas sociales y culturales apoyan y valoran el éxito } \\
\text { individual se consiguió a través del esfuerzo personal. }\end{array}$ & & 50.0 & 25.0 & & 25.0 \\
\hline
\end{tabular}

La dimensión de normas sociales y culturales presenta resultados que demuestran de acuerdo a las respuestas de los expertos que no hay y no existen influencia en la creatividad, riesgo e iniciativa en los emprendedores por parte de la sociedad empero si están de acuerdo que son responsables de gestionar su propia vida y valoran el esfuerzo personal por lo cual se considera que la responsabilidad para aperturar negocios es propia del esfuerzo personal de aquellos que se deciden a emprender un negocio.

\section{Conclusiones}

Los expertos en el estado de Sonora reconocen que sí existe una actitud positiva para emprender un negocio y consideran que las oportunidades para aperturar una empresa son favorables, sin embargo, hay condiciones que impiden que esto se dé en ciertos sectores. Los apoyos por parte del gobierno para impulsar la economía mediante políticas y programas dirigidos a los nuevos emprendedores y al crecimiento de los empresarios establecidos por el momento no existen o están ausentes en aquellas áreas donde el gobierno pudiera impulsar el desarrollo económico del municipio de Hermosillo, por lo que habría que hacerle saber, de los beneficios que implicaría el apoyo a estos sectores.

Las condiciones sociales muestran un ambiente propicio en el cual los expertos consideran que los emprendedores están motivados a emprender, confían en sus capacidades, tienen ideas del tipo de negocio que desean, en todo momento 
Año 13.

Revista de Investigación

Núm. 33

Académica sin Frontera

https://revistainvestigacionacademicasinfrontera.unison.mx/index.php/RDIASF

Recibido el 14 de abril de 2020. Dictaminado mediante arbitraje favorablemente 9 de julio de 2020.

muestran una actitud que demuestra que los mercados son idóneos para recibir nuevos negocios, por lo que no es por falta de emprendedores el problema, sino, como se dijo en el párrafo anterior, es por cierta falta de apoyo a diversos sectores; sin embargo, se proyecta el crecimiento económico sostenido en el futuro inmediato en la ciudad de Hermosillo, Sonora.

Es necesario que emprendedores y gobierno coordinen esfuerzos y ambos generen el crecimiento económico mediante la apertura de nuevos negocios y se generen los empleos que el que la cuidad de Hermosillo Sonora necesita.

\section{Referencias}

Alcaraz, R. (2011). El emprendedor con éxito. MéxicoMc Graw-hill: Interamericana Editores S.A. de C.V.

Castillo, C. (10 de Septiembre de 1999). Estado del arte en la enseñanza del emprendimiento. Obtenido de Estado del arte en la enseñanza del emprendimiento: http//www.aaep.org.ar/anales/works/works2007/formichella.pdf

Fernández Laviada, A. (2015). Informe GEM España 2014. España: Universidad de Cantabria.

Fernández Laviada, A. (2015). Informe GEM España 2014. España: Universidad de Cantabria.

Hisrich, R., Peters, M., \& Shepherd, D. (2005). Entrepreneurship (Sexta ed.). México: Mc Graw Hill.

Hisrich, R., Peters, M., \& Shepherd, D. (2005). Entrepreneurship (Sexta ed.). México: Mc Graw Hill.

Leiva Bonilla, J. C. (2007). Los Emprendedores y la Creación de Empresas. Costa Rica: Tecnologica de Costa Rica.

Leiva Bonilla, J. C. (2007). Los Emprendedores y la Creación de Empresas. Costa Rica: Tecnologica de Costa Rica. 
Año 13.

Revista de Investigación

Núm. 33

Académica sin Frontera

https://revistainvestigacionacademicasinfrontera.unison.mx/index.php/RDIASF

Recibido el 14 de abril de 2020. Dictaminado mediante arbitraje favorablemente 9 de julio de 2020.

Porter, M. (2002). Executive Summary: Competitiveness and Stages of Economic Development. Estados Unidos: Oxford University.

Porter, M. (2002). Executive Summary: Competitiveness and Stages of Economic Development. Estados Unidos: Oxford University.

Querejazu, V. (2015). Reporte Nacional Bolivia 2014. Bolivia: Universidad Catolica Boliviana "San Pablo".

Querejazu, V. (2015). Reporte Nacional Bolivia 2014. Bolivia: Universidad Catolica Boliviana "San Pablo".

Reynolds, P. (1999). Global Entrepreneurship Monitor, 1999 Executive Report. Estados Unidos: Kauftman Foundation.

Rockefeller, D. (10 de Septiembre de 2006). Gestión efectiva de emprendimentos sociales. Obtenido de Gestión efectiva de emprendimentos sociales: http://books.google.com.mx

Reynolds, P. (1999). Global Entrepreneurship Monitor, 1999 Executive Report. Estados Unidos: Kauftman Foundation.

Singer, S. (2015). Global Entrepreneurship Monitor 2014 Global Report. Estados Unidos: Babson College.

Sánchez, J. (10 de Septiembre de 2014). Actitud emprendedora y oportunidades de negocio. Obtenido de Actitud emprendedora y oportunidades de negocio: http://books.google.com.mx

Singer, S. (2015). Global Entrepreneurship Monitor 2014 Global Report. Estados Unidos: Babson College. 
Año 13.

Revista de Investigación

Núm. 33

Académica sin Frontera

ISSN: 2007-8870

https://revistainvestigacionacademicasinfrontera.unison.mx/index.php/RDIASF

Recibido el 14 de abril de 2020. Dictaminado mediante arbitraje favorablemente 9 de julio de 2020.

\section{Directorio Institucional}

Dr. Enrique Fernando Velázquez Contreras

Rector

Dr. Ramón Enrique Robles Zepeda

Secretario General Académico

Dra. Rosa María Montesinos Cisneros

Secretaria General Administrativa

Dr. Rodolfo Basurto Álvarez

Director de Vinculación y Difusión

Dra. Adriana Leticia Navarro Verdugo

Vicerrectora de la Unidad Regional Sur

Dr. Ernesto Clark Valenzuela

Director de la División de Ciencias Económicas y Sociales 
Año 13.

Revista de Investigación

Núm. 33

Académica sin Frontera

https://revistainvestigacionacademicasinfrontera.unison.mx/index.php/RDIASF

Recibido el 14 de abril de 2020. Dictaminado mediante arbitraje favorablemente 9 de julio de 2020.

Dr. Francisco Espinoza Morales

Secretario de la División de Ciencias Económico y Sociales

Dra. Leticia María González Velásquez

Jefe del Departamento de Ciencias Económico Administrativas

Dra. Lidia Amalia Zallas Esquer

Jefe de Departamento de Ciencias Sociales

\title{
Comité Directivo
}

\author{
Editor Responsable \\ Dr. Francisco Espinoza Morales
}

Directora

Dra. Leticia María González Velásquez

Subdirector

Dr. Javier Carreón Guillen

\section{Editor Científico}

Dr. Cruz García Lirios 
Año 13.

Revista de Investigación

Núm. 33

Académica sin Frontera

ISSN: 2007-8870

https://revistainvestigacionacademicasinfrontera.unison.mx/index.php/RDIASF

Recibido el 14 de abril de 2020. Dictaminado mediante arbitraje favorablemente 9 de julio de 2020.

\section{Master Gráfico}

M.T.I. Francisco Alan Espinoza Zallas

Nos complace anunciar que su diario, "Academic Research Journal Withoutborders" (ISSN/EISSN 2007-8870) fue evaluado positivamente en la indexación Citefactor, ahora la página de la revista está disponible en línea, en caso de cualquier problema.

Journals Master | International Innovative Journal Impact Factor (IIJIF)

Red Latinoamericana de revistas Académicas en Ciencias Sociales y Humanidades
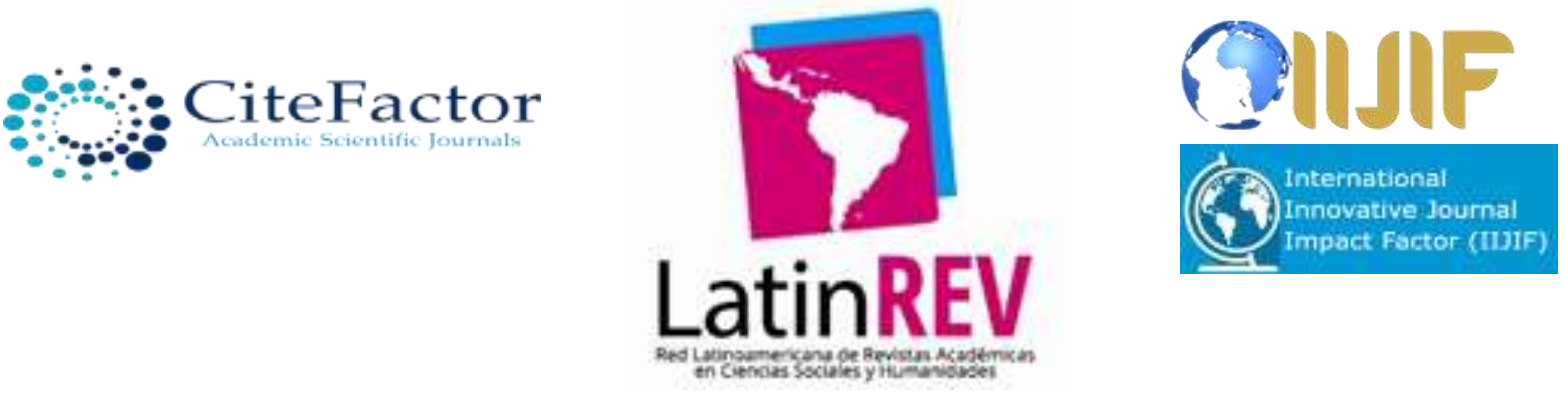

\section{Comité editorial}

Dra. Angélica María Rascón Larios

Universidad de Sonora. México

Dra. María del Rosario Molina González

Universidad de Sonora

Dra. Francisca Elena Rochin Wong

Universidad de Sonora. México

Dra. Lidia Amalia Zallas Esquer

Universidad de Sonora. México

Dra. Beatriz Llamas Arechiga

Universidad de Sonora. México 
Año 13.

Revista de Investigación

Núm. 33

Académica sin Frontera

https://revistainvestigacionacademicasinfrontera.unison.mx/index.php/RDIASF

Recibido el 14 de abril de 2020. Dictaminado mediante arbitraje favorablemente 9 de julio de 2020.

Dr. Rogelio Barba Álvarez

Universidad de Guadalajara. México

Dra. Rosa María Rincón Ornelas

Universidad de Sonora. México

Dr. Juan Flores Preciado

Universidad de Colima. México

Dr. Amado Olivares Leal. Universidad de Sonora

Universidad de Sonora. México

Dr. Guillermo Velázquez Valadez.

Instituto Politécnico Nacional (IPN) México

Dr. Hugo Nefstalí Padilla Torres.

Universidad Estatal de Sonora. México

Dr. Luis Ramón Moreno Moreno.

Universidad Autónoma de Baja California. México

Dr. Miguel Ángel Vázquez Ruiz.

Universidad de Sonora. México

Dra. Lorena Vélez García.

Universidad Autónoma de Baja California. México

Dra. Pabla Peralta Miranda.

Universidad Simón Bolívar, Barranquilla, Colombia

Mtro. Roberto Espíritu Olmos

Universidad de Colima (FCA Tecomán) Colima

Dr. Héctor Priego Huertas.

Universidad de Colima (FCA Tecomán) Colima

Mtra. María Guadalupe Alvarado Ibarra.

Universidad de Sonora. México.

MSc. Celso Germán Sánchez Zayas 
Año 13.

Revista de Investigación

Núm. 33

Académica sin Frontera

https://revistainvestigacionacademicasinfrontera.unison.mx/index.php/RDIASF

Recibido el 14 de abril de 2020. Dictaminado mediante arbitraje favorablemente 9 de julio de 2020 .

Universidad de Camagüey, Ignacio Agramonte Loynaz, Cuba

Dra. María Luisa Quintero Soto

Universidad Autónoma del Estado de México

Dr. Eyder Bolivar Mojica

Universidad Católica, Luis Amigó, Medellin, Colombia

Revisores de Textos en Inglés

Mtro. Renato Encinas

Mtra. Cecilia Guadalupe Martínez Solano

Comité científico

Dr. Rosendo Martínez Jiménez. Universidad Autónoma Benito Juárez de Oaxaca.

Dr. Hugo Neftalí Padilla. Universidad Estatal de Sonora

Dra. María Teresa Gaxiola Sánchez. Universidad de Sonora.

Dr. José Cesar Kaplan. Universidad Estatal de Sonora.

Dr. Alfredo Islas Rodríguez. Universidad de Sonora

Frecuencia de publicación: semestral / 2 números por año.

Revista de Investigación Académica sin Frontera (RIASF) con (ISSN: 2007-8870) es un interlocutor internacional de acceso abierto revisado diario en línea en el ámbito del de las Ciencias Económicas Administrativas y Sociales. Su objetivo principal es dar a los trabajos de investigación de calidad. Cubre todas las sub-campos de los campos anteriormente mencionados. Proporciona la plataforma a académicos, estudiantes y profesionales. Sólo pública trabajos de investigación y artículos de revisión inicial. Documento presentado debe cumplir con algunos criterios como, debe ser original, inédita y no estén sometidos a ninguna otra revista.

RIASF es una revista arbitrada / Revisión por pares International. Publicamos documentos sobre una variedad de temas, contextos y estrategias de análisis que examinan la relación entre la rápida evolución para la Sociedad y la tecnología del conocimiento.

REVISTA DE INVESTIGACIÓN ACADÉMICA SIN FRONTERA, Año 13, No. 33, Julio - diciembre 2020, es una publicación semestral de investigación científica, editada por la Universidad de Sonora, a través de las División de Ciencias Económicas y Sociales, de la Unidad Regional Sur, Blvd. Lázaro 
Año 13.

Revista de Investigación

Núm. 33

Académica sin Frontera

https://revistainvestigacionacademicasinfrontera.unison.mx/index.php/RDIASF

Recibido el 14 de abril de 2020. Dictaminado mediante arbitraje favorablemente 9 de julio de 2020 .

Cárdenas No. 100, Col. Francisco Villa, Navojoa, Sonora, Sonora, México, C.P. 85880. Tel. (642) 42599-54.

http://www.revistainvestigacionacademicasinfrontera.com/, revistaacademicasinfrontera@unison.mx. Editor responsable: Francisco Espinoza Morales. Reserva de Derechos al Uso Exclusivo: 042013-121811323700-203 e ISSN: 2007-8870, ambos otorgados por el Instituto Nacional de Derecho de Autor. Inscrita en el Directorio de LATINDEX, con Núm. De folio 20014, folio único 14590. Responsable de la última actualización de este Número, Unidad Informática de la Universidad de Sonora, fecha de la última modificación, 30 de diciembre 2020, indexada a Cite Factor Academic Scientific Journal y Journals Master (IIJIF) y Red Latinoamericana de Revistas Académicas en Ciencias Sociales y Humanidades, (Latín Rev). Las opiniones expresadas por los autores no necesariamente reflejan la postura del editor de la publicación. Se autoriza la reproducción total o parcial de los contenidos e imágenes en la presente publicación siempre y cuando se cuente con la autorización del editor y se cite plenamente la fuente.

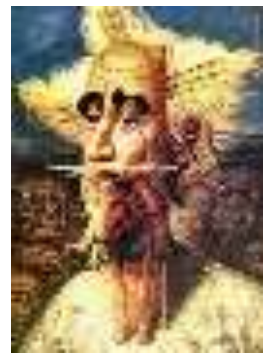

Nos complace anunciar que su diario, "Academic Research Journal Withoutborders" (ISSN/EISSN 2007-8870) fue evaluado positivamente en la indexación Citefactor, ahora la página de la revista está disponible en línea, en caso de cualquier problema.

Journals Master | International Innovative Journal Impact Factor (IIJIF) 
Revista de Investigación

Núm. 33

Académica sin Frontera

https://revistainvestigacionacademicasinfrontera.unison.mx/index.php/RDIASF

Recibido el 14 de abril de 2020. Dictaminado mediante arbitraje favorablemente 9 de julio de 2020.

Red Latinoamericana de revistas Académicas en Ciencias Sociales y Humanidades
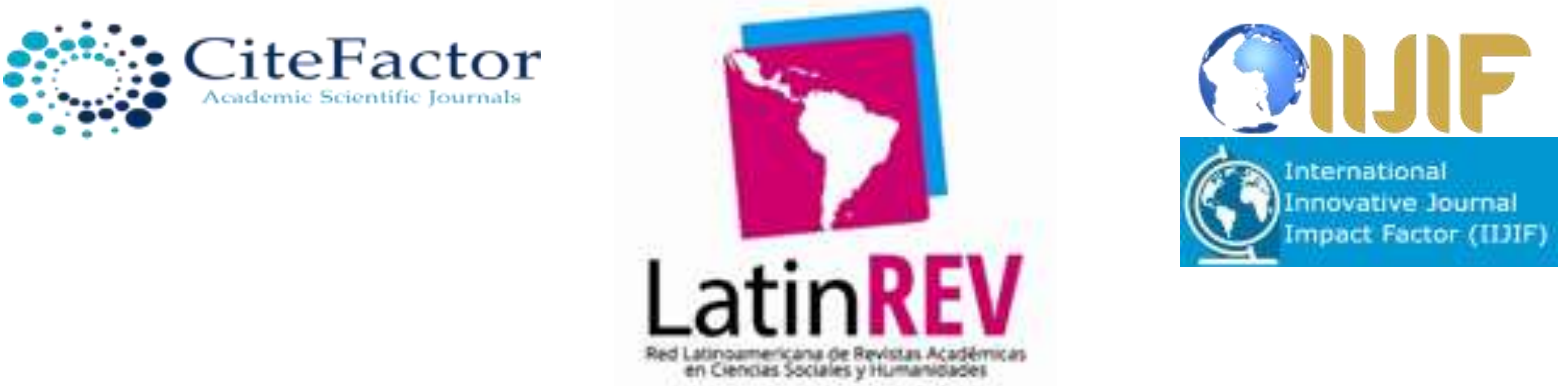

\section{https://www.neliti.com}
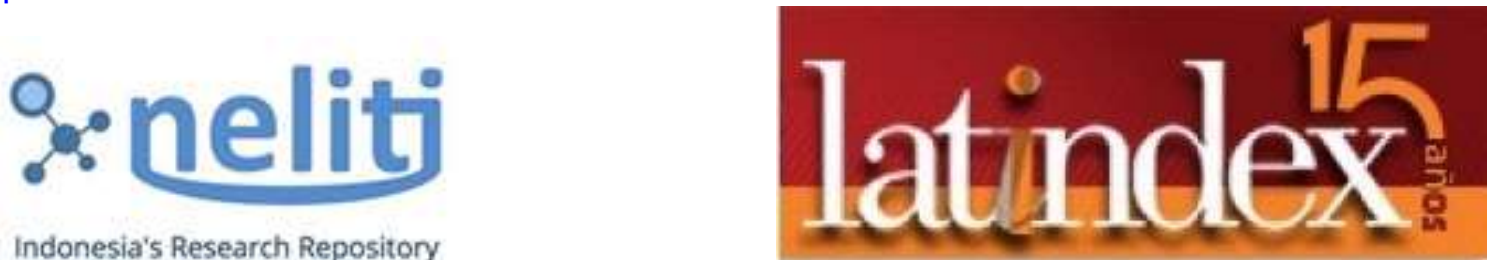

Indonesia's Research Repository 